\title{
Smoking Cigarettes, Marijuana, and the Transition to Marriage among Cohabiters in the USA
}

\author{
Ali Roghani ${ }^{1}$. Samuel H. Nyarko ${ }^{1}$. Lloyd Potter ${ }^{1}$
}

Accepted: 27 April 2021 / Published online: 5 May 2021

(c) The Author(s) 2021

\begin{abstract}
Many studies have established that married people have lower rates of smoking than singles and cohabiters. However, there is still limited research showing whether this advantage also applies specifically to cohabiters before marriage. Hence, this study examines the association between cigarette and marijuana smoking and the transition to marriage among cohabiters in the USA. This study employs data from seventeen waves of the National Longitudinal Survey of Youth 1997. Discrete-time logistic regression models are used to test whether lower rates of cigarette and marijuana smoking among cohabiters are associated with the transition to marriage. Results indicate that lower levels of marijuana and cigarette smoking are associated with the transition to marriage among male and female cohabiters. Not smoking cigarettes and marijuana is associated with a significantly higher odds of transition to marriage for both sexes. The findings show that smoking status may play a significant role in the odds of getting married during cohabitation. Pro-marital policies can focus on addressing smoking habits among cohabiters.
\end{abstract}

Keywords Smoking $\cdot$ Cigarette $\cdot$ Marijuana $\cdot$ Transition to marriage $\cdot$ Cohabiter

\section{Background}

The transition to adulthood is a vital stage in life with key events such as family formation and parenthood (Furstenberg et al., 2005; Roghani et al., 2021; Schulenberg et al., 2004). Heterogeneity in the types of family formation among young adults may have increased in recent decades (Oesterle et al., 2010). Various factors such as marijuana and cigarette smoking are associated with family formation behaviors (Johnston et al., 2016). Meanwhile, research has indicated that young adults who directly enter marriage from single life are more likely to be motivated to accept social norms, whereas it is not clear whether cohabitation motivates young adults to accept social norms as marriage does (Hoffmann, 2018).

To better understand the difference between cohabitation and marriage regarding substance use behavior, it is important to distinguish between these two types of family formation. Cohabitation is regarded as a more secular and nontraditional union, whereas marriage is governed by more rigid

Ali Roghani

ali_roghani@hotmail.com

1 Department of Demography, College for Health, Community \& Policy, University of Texas, San Antonio, USA social norms, and the roles of husbands and wives are clearly defined (Klärner, 2015). Marriage usually entails monogamy and long-term commitment, and married couples have a responsibility to maintain social norms that are necessary for avoiding risky health behaviors such as marijuana smoking (Duncan et al., 2006; Fleming et al., 2010; Ali \& Ajilore, 2011). Thus, the lifestyle governed by marriage is generally different from that of single life and some types of cohabitation, both of which may be more tolerant of risky behaviors.

Existing research has shown that cohabitation increases the risk of substance use and does not change substance use behaviors (Hoffmann, 2018). Meanwhile, cohabitation has become a pathway into marriage among recent American generations, taking the same role as engagement, and a great number of cohabiters eventually enter marriage (Manning, 2020). Furthermore, previous research has linked a reduction in health-risk behaviors to marriage, particularly for men (Shrout \& Kiecolt-Glaser, 2020). Existing research also indicates that cigarette use is associated with a delay in marriage for females, while marijuana use is associated with a delay in marriage for males (Jang et al., 2018). However, it has been observed that the nexus between risky health behaviors and the transition from cohabitation to marriage has received relatively little attention (Duncan et al., 2006). 
Thus, there is a gap in the literature concerning the association between heterosexual cohabitation, substance use, and the eventual transition to marriage among cohabiters. As such, the current study examines whether rates of smoking cigarettes and marijuana among cohabiters are associated with the transition to marriage in the USA.

We expect lower levels of substance use to be associated with higher odds of transition to marriage relative to remaining in cohabitation or breaking up. We also stratify our analysis by sex, which is an integral part of union formation (Jackson, 2012), and we expect the associations of marijuana and cigarette with the transition to marriage to be similar. Although smoking cigarettes is a longer-lasting behavior, avoiding smoking marijuana may be more influential in the transition to marriage among cohabiters (Fedorova et al., 2020). Additionally, this study considers mental health indicators, which may be crucial for the stability of the relationships (Percheski \& Meyer, 2018) and are significantly associated with using substances (Guttmannova et al., 2017). In this regard, it may be noteworthy that for females, mental health may improve after the formation of unions, whether marriage or cohabitation, while men's mental health status may improve after marriage (Rapp \& Stauder, 2019). This study, therefore, provides a deep understanding of the role substance use may play concerning the transition from cohabitation to marriage among heterosexual cohabiters in the USA.

\section{Materials and Methods}

\section{Data Source}

This study draws on data from the National Longitudinal Study of Youth 1997 (NLSY97). This is a prospective nationally representative survey of youth from the birth cohort of 1980-1984 in the USA. The first wave started in 1997 when the participants were between the ages of 12 to 18 . The NLSY97 repeatedly collects data on several issues including measures of union formation, and substance use behaviors, and, therefore, provides the opportunity to examine the transition from cohabitation to marriage among the participants. The NLSY97 used a multi-stage stratified area probability sampling procedure to select participants from dwelling units and group quarter units in the USA. This study deployed all the seventeen waves until 2015 when respondents were between 30 and 36 years old. The unit of analysis is all respondents who were never married but were cohabitating between 1997 and 2015. Thus, a final sample size of 2178 is composed of study participants with data on their characteristics, and life course events pertinent to the study were used for the analysis.

\section{Study Variables and Measurements}

The outcome variable is whether cohabitation unions have ended in marriage. In the first wave, there were 143 cases that reported cohabitation with most of the sample being less than 16 years. The NLSY97 asks respondents their current marital status as well as the month and year of cohabitation and marriage after the age of 16 . Therefore, we captured short cohabitations in addition to cohabitations that took more than 1 year in the middle of the study duration. Cohabiting respondents who broke up in the subsequent waves were, however, removed from the risk set. In the current study, we examine two main predictor variables such as cigarette and marijuana smoking. These variables were measured in each wave to denote the number of days respondents have used cigarettes and marijuana in the last 30 days. Arbitrary cutoffs were applied to change the continuous formats of smoking cigarettes and marijuana to categorical variables (Shang, 2012). The number of cigarette smoking days was used to create three categories, such as non-smoking (0 day), intermittent smoking (1-23 days for females, 1-24 days for males), and daily smoking (24-30 days for females, 25-30 days for males). For Marijuana smoking, 0 day of smoking was categorized as non-smoking; 1-21 days and 1-22 days of smoking were categorized as intermittent smoking for females and males, respectively, while 22-30 days and 23-30 days were categorized as daily smoking for females and males, respectively.

Also, factors such as race/ethnicity, educational status, overall health, parental divorce, and childbirth with a partner were included as control variables in the analysis. Race/ethnicity was coded into three categories as White, Black, and Hispanic. Other miscellaneous races included in the NLSY97 were less than $1 \%$ of the main data. Consequently, only 9 young adults from these minority races were found in our sample; therefore, we excluded this group from our final sample for the analysis due to statistical power concerns. Educational attainment was categorized into four groups as less than high school, high school, some college, and college degree or more. Regarding overall health, respondents who reported "poor" health were coded as poor whereas other health conditions were coded as good health. A family structure variable was created to indicate whether respondents came from an intact family or experienced parental divorce or death. The transition to parenthood was constructed based on dates in months and years when respondents have had their first child. For mental health, NLSY asked questions regarding the level of anxiety using a scale of 1 to 7 , where 1 means strongly disagree, and 7 means strongly agree. This was re-coded in three categories, where 1 to 3 were coded 
as disagree, 4 was coded as neither agreed nor disagree (neutral), and 5 to 7 were coded as agree. For depression level, respondents reported how often they were depressed in the past month. This variable was measured in three categories as "most of the time," "some of the time," and "none of the time."

\section{Analytic Strategy}

Data processing and analysis were done with the $\mathrm{R}$ programming language ( $\mathrm{R}$ version 3.6.1) ( $\mathrm{R}$ Core Team, 2018). The final sample was organized into a person-period file for all current cohabiters, with separate records for each respondent for each year. This was used to generate descriptive results on the background characteristics of the sample in the form of tables and figures. Kaplan-Meier survival techniques were applied to estimate how the timing of the transition to marriage varied by gender (see Fig. 3). Further, a discrete-time logistic regression was applied to test the association between two main predictors — cigarette and marijuana smoking — and the transition from cohabitation to marriage among cohabiters in the sample. Three models were fitted and stratified by sex. Model 1 examined the effects of cigarette smoking for both sexes while model 2 examined the influence of marijuana smoking. Model 3 is the full model and controlled for the background characteristics of the respondents and some mental health indicators such as the feeling of anxiety and depression. The results were summarized in odds ratios with 95\% confidence intervals. The results were weighted using the complex survey weighting procedure.

\section{Results}

\section{Descriptive Results}

Table 1 shows the descriptive results of the background characteristics of the study sample. More than half (52\%) of the sample was White, while Black and Hispanic were around 28 and $18 \%$, respectively. More than $50 \%$ of the sample had high school diplomas, and more women had advanced degrees than men ( $31 \%$ and $28 \%)$. About one-tenth of the sample had poor health while more than a quarter had experienced parental divorce. Also, about $46 \%$ of men and $53 \%$ of cohabitating women had a child with their partner. Moreover, only about $17 \%$ of cohabitating men and $24 \%$ of women had eventually transitioned to marriage. Around 45\% were daily cigarette smokers, while only a few never smoked cigarettes $(12.5 \%$ and $9.1 \%$ for males and females respectively). A total of $46.6 \%$ of males and $69.4 \%$ of females were intermittent marijuana smokers whereas more than one-third (36.3\%) of males never smoked marijuana. These had reflected in the smoking rates among males and females
Table 1 Descriptive results of constant and time-varying characteristics, and those who made the transitions (NLSY97)

\begin{tabular}{|c|c|c|}
\hline & Males (\%) & Females $(\%)$ \\
\hline \multicolumn{3}{|l|}{ Race/ethnicity (c) ${ }^{\mathrm{b}}$} \\
\hline White & 52.4 & 53.2 \\
\hline Black & 27.8 & 28.1 \\
\hline Hispanic & 19.8 & 18.7 \\
\hline \multicolumn{3}{|l|}{ Education status ${ }^{\mathrm{c}}$} \\
\hline Less than high school & 8.7 & 7.6 \\
\hline High school & 54.5 & 54.3 \\
\hline Some college & 8.3 & 07.1 \\
\hline College degree or more & 28.5 & 31.0 \\
\hline \multicolumn{3}{|l|}{ Overall health } \\
\hline Poor & 11.9 & 11.1 \\
\hline Good & 88.1 & 88.9 \\
\hline \multicolumn{3}{|l|}{ Family structure $(C)^{b}$} \\
\hline Parental divorce & 26.1 & 27.7 \\
\hline Intact family & 63.1 & 61.7 \\
\hline Parental death & 10.8 & 10.6 \\
\hline Have a child with the partner ${ }^{c}$ & 46.0 & 53.5 \\
\hline Cohabitations end in marriage & 16.9 & 23.7 \\
\hline Smoking $^{c}$ & 10.9 & \\
\hline Non-smoking & 12.5 & 09.1 \\
\hline Intermittent smoking & 42.4 & 47.5 \\
\hline Daily smoking & 45.1 & 43.4 \\
\hline \multicolumn{3}{|l|}{ Marijuana $^{\mathrm{a}}$} \\
\hline Non-smoking & 36.3 & 17.8 \\
\hline Intermittent smoking & 46.4 & 69.4 \\
\hline Daily smoking & 17.3 & 12.8 \\
\hline \multicolumn{3}{|l|}{ Feeling anxious ${ }^{c}$} \\
\hline Disagree & 55.8 & 44.0 \\
\hline Neutral & 20.3 & 44.4 \\
\hline Agree & 13.9 & 11.6 \\
\hline \multicolumn{3}{|l|}{ Feeling depressed ${ }^{c}$} \\
\hline None of the time & 62.9 & 54.3 \\
\hline Some of the time & 7.4 & 9.5 \\
\hline Most of the time & 29.7 & 36.2 \\
\hline
\end{tabular}

${ }^{\text {a }}$ These variables are asked in the 2013 wave

${ }^{\mathrm{b}}$ These variables are asked in the first wave of the survey (1997)

${ }^{\mathrm{c}}$ These variables are asked in the 2015 wave

by single ages as shown in Figs. 1 and 2. A considerable proportion of the sample from the ages of 15 to 32 was daily cigarette smokers, and these rates did not change considerably. More than half of the male sample (56\%) and about $44 \%$ of the females reported that they never felt anxious. Regarding depression, men had a lower rate of depression than females, with about $37 \%$ of men and $46 \%$ of women reporting ever feeling depressed. The survival analysis indicates that nearly half of male and female cohabiters eventually got married; however, most of the transition to 

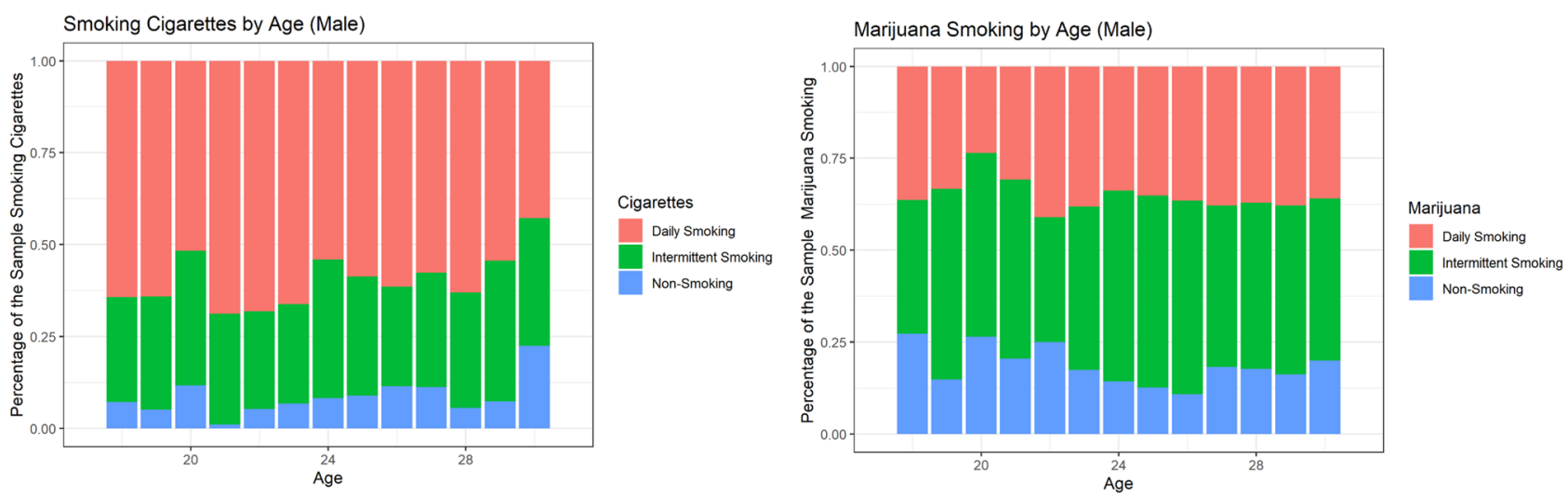

Fig. 1 Cigarette and marijuana smoking by age among males

marriage was after the age of 25 (see Fig. 3). This shows that although we traced the cohort from 1997, most of the events in the analysis happened after 2010.

\section{The Transition from Cohabitation to Marriage}

Table 2 shows a summary of results from the analysis of the transition to marriage among the study sample. Male cohabiters who never smoked cigarettes were more likely to marry than daily and intermittent smokers (62 and 51\%, respectively). In model 3, the odds ratio decreased by about $10 \%$ after adjusting for control variables. Female daily smokers were less likely to be married by their cohabiting partners $(\mathrm{OR}=0.33, p=0.001$, model $1 ; \mathrm{OR}=0.47, p=0.05$, model 3). Although model 1 indicates that there was no significant relationship between non-smoking and intermittent smoking, by including the control variables, the association became significant and even stronger than that of daily smokers $(\mathrm{OR}=0.41$, $p=0.01$, model 3 ). While intermittent marijuana smoking

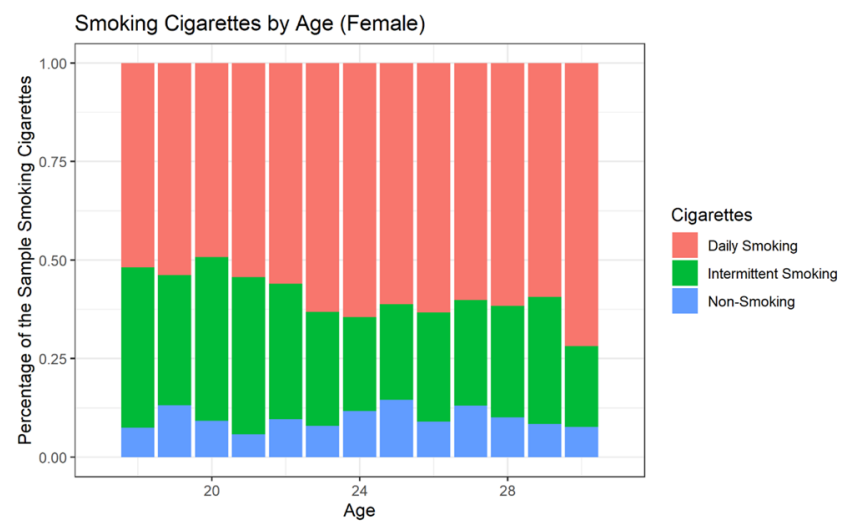

was not associated with the transition to marriage, nonsmoking had a significantly higher likelihood of marriage than daily marijuana smoking for males and females. In the first model, men who were daily marijuana smokers had $40 \%$ lower odds of marrying, while females had $48 \%$ lower odds. By adjusting for control variables, the association appeared to be attenuated but remained significant. As indicated in Figs. 4 and 5, non-smokers were more likely to marry in every age by types of smoking among females and males.

Higher educational attainment appeared to be associated with increased odds of making a transition to marriage among both male and female cohabiters. Having a child with a partner during cohabitation was not associated with making a transition to marriage. Having a higher level of anxiety was associated with about $40 \%$ lower odds of transition to marriage for both males and females. The results also indicate that female cohabiters who had depression some of the time and most of the time were $29 \%$ and $6 \% 5$ less likely to enter marriage, respectively.

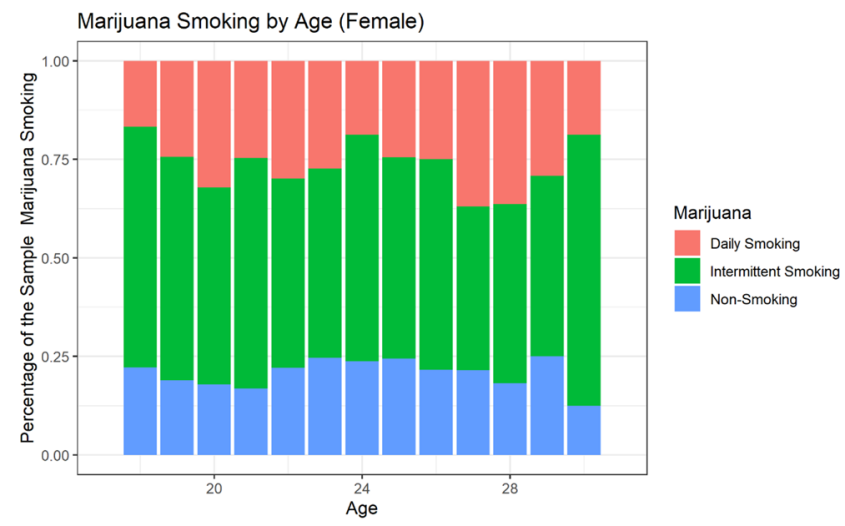

Fig. 2 Cigarette and marijuana smoking by age among females 
Fig. 3 Survival analysis of the transition to marriage among cohabiters

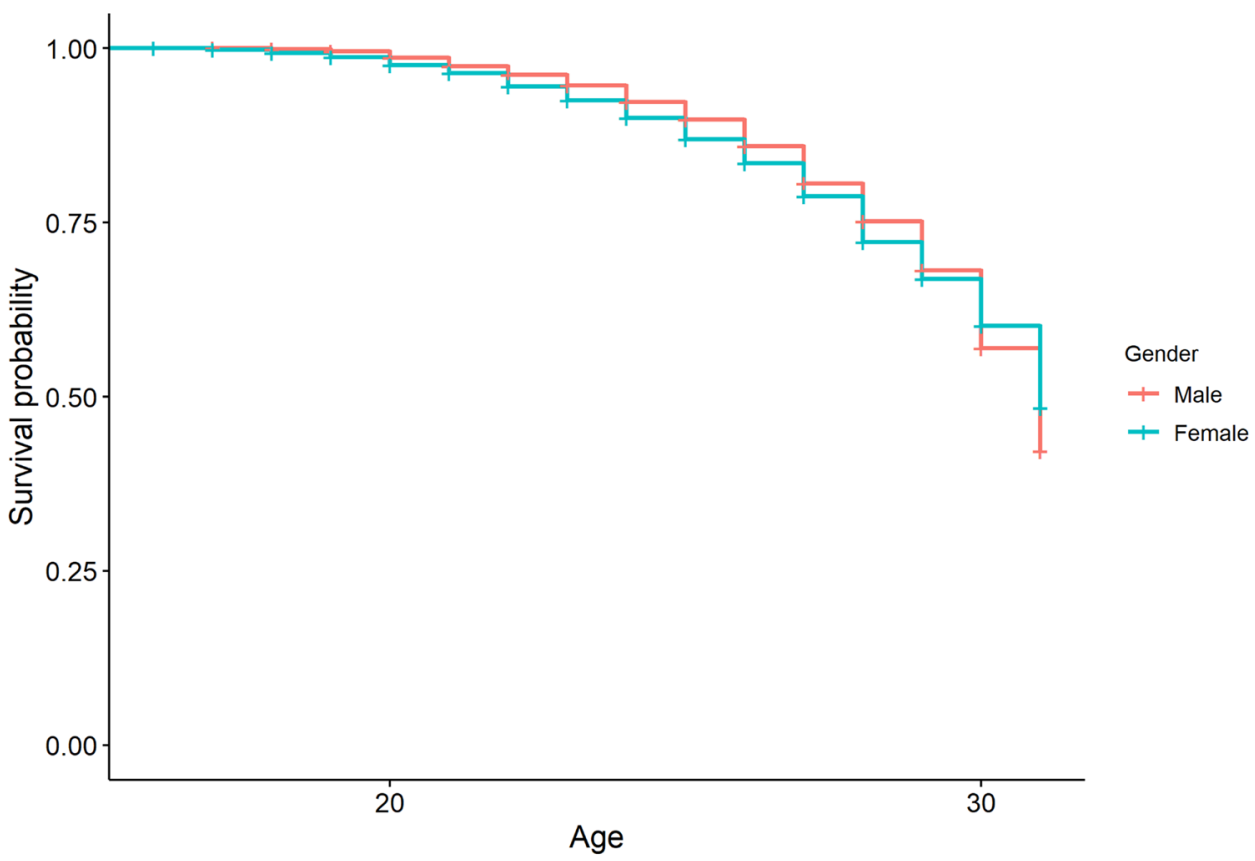

\section{Discussion}

The findings of the current study provide some evidence of the association between cigarette and marijuana smoking behavior and the transition to marriage among cohabitating young American adults. The descriptive findings indicate that cigarette and marijuana smoking are highly prevalent among cohabiting young adults in the USA, and smoking rates do not seem to vary considerably over the life course until age 32 . This mainly includes daily cigarette smokers and intermittent marijuana smokers. Hence, it appears that the rate of smoking cigarettes among young American adults is substantially higher than that of marijuana smoking for both sexes.

Furthermore, the findings show that smoking behavior is significantly associated with the transition from cohabitation to marriage among male and female cohabiters. Essentially, intermittent and daily smoking of cigarettes and marijuana are associated with significantly lower odds of getting married during cohabitation. As a corollary, not smoking cigarettes and marijuana during cohabitation appears to boost the chances of marriage considerably. This positive implication of not smoking appears to persist throughout the ages from 15 to 32 for both sexes. It has been shown that married couples have lower risky behaviors (Duncan et al., 2006; Fleming et al., 2010; Ali \& Ajilore, 2011) and are more likely to have better health (Perelli-Harris et al., 2018; Tumin \& Zheng, 2018). Previous research has shown that partners affect each other's health behaviors (Jackson et al., 2015), by monitoring and managing their health behaviors (Umberson, 1992). These healthy daily interaction patterns can help the partners to have more stable relationships in their cohabitation and eventually move to marriage. Therefore, this important advantage of not smoking may show that some American young adults may be cohabitating as a "trial of marriage" (Li et al., 2020), by considering the smoking behavior of their partners among others before deciding to make a transition to marriage.

Similarly, this may be an indication that the transition from cohabitation to marriage among American young adults is mainly the result of selection based on social norms barring cigarettes and marijuana smoking. This may follow the fact that unlike cohabitation, marriage serves as an agency of social control (Kulu \& Boyle, 2010), and cohabiters may selectively want to marry people who adhere to social norms. However, cohabiters do not always have healthy behaviors, and a great proportion of cohabitations do not end in a marriage.

As well, the relationship between partnership status and smoking may depend considerably on educational attainment (Margolis \& Wright, 2016) as cohabiters with an advanced degree are most likely to transition to marriage. Our findings further show that feeling of anxiety appears to significantly constrain the chances of transition to marriage among cohabiters for both sexes. Essentially, having no anxiety appears to be a considerable boost to the transition to marriage among cohabiters. Analogously, this study also finds that suffering from depression considerably limits the chances of transitioning to marriage among female cohabiters. However, this effect appears weak for male cohabiters, and it is unclear why this may be so. Perhaps, this may have something to do with the magnitude of depressed 
Table 2 Factors predicting transforming cohabitation to marriage by logistic regression model (odds ratios), NLSY97

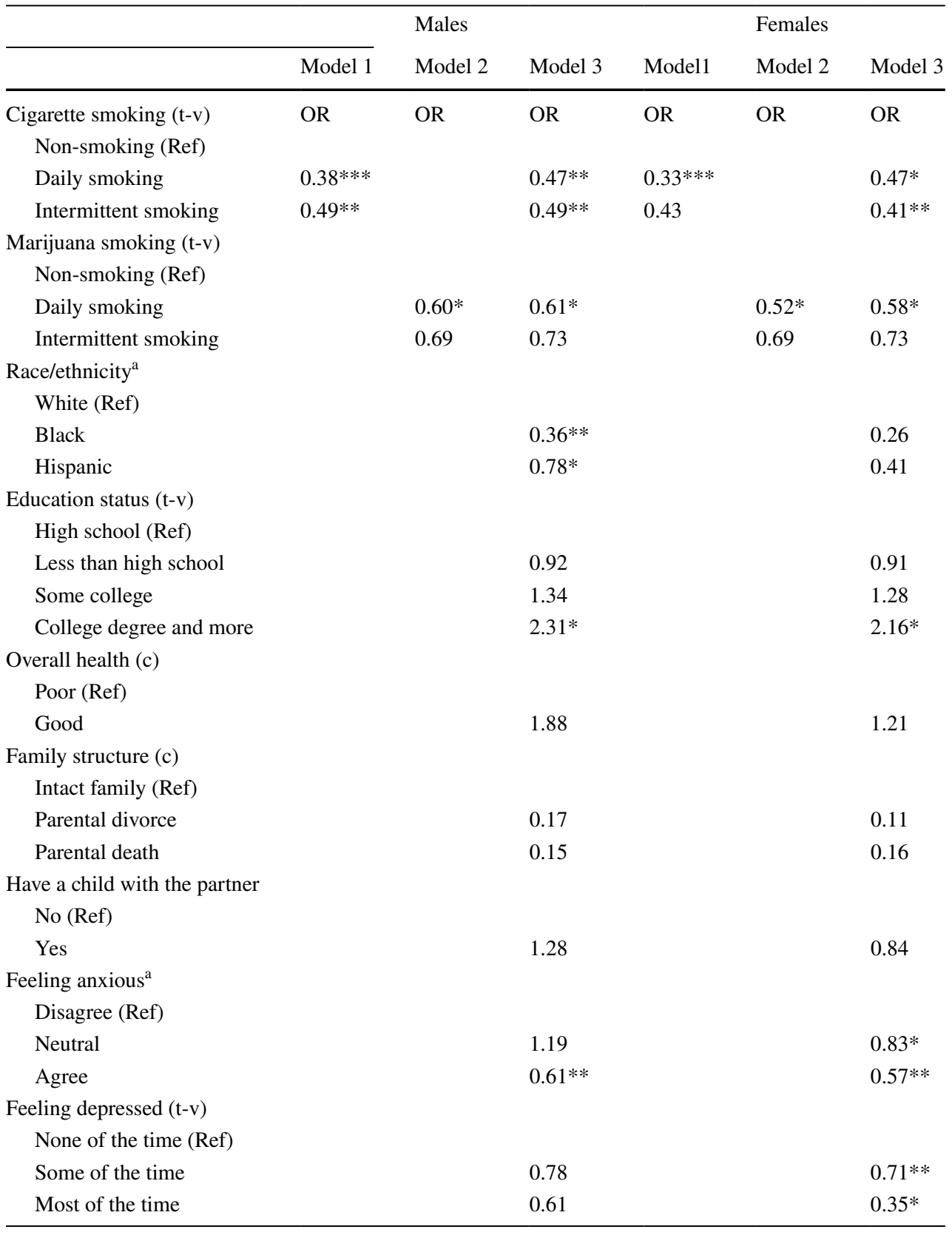

$O R$ odds ratios, significance, $t-v$ time varying variable

$* * * p<0.001 ; * * p<0.01 ; * p<0.05$

${ }^{\text {a }}$ These variables were measured one point men compared to women. Mental health domains-anxiety and depression - as studied in this research have, therefore, shown a significant association with the marital chances of cohabiters with the mentally healthy cohabiters having a disproportionate advantage in the transition to marriage. Some studies have linked marriage to considerable mental health benefits (Tumin \& Zheng, 2018; Uecker, 2012). Conversely, the findings of this study imply that the transition to marriage may also be due to the positive selection of cohabiters based on their mental health, and thereby echoing the argument that the association between marriage and mental health may be partly due to selection (Jo, 2020).

This study has a few potential limitations. First, NLSY97 does not provide information on cohabiters' smoking behavior that we were unable to examine assortative mating in this study. Additionally, the data are based on self-reports of young adults. However, previous research contends that substance-using behaviors are underreported (Krumpal, 2011). Therefore, there may be a degree of bias that may influence the findings of this 

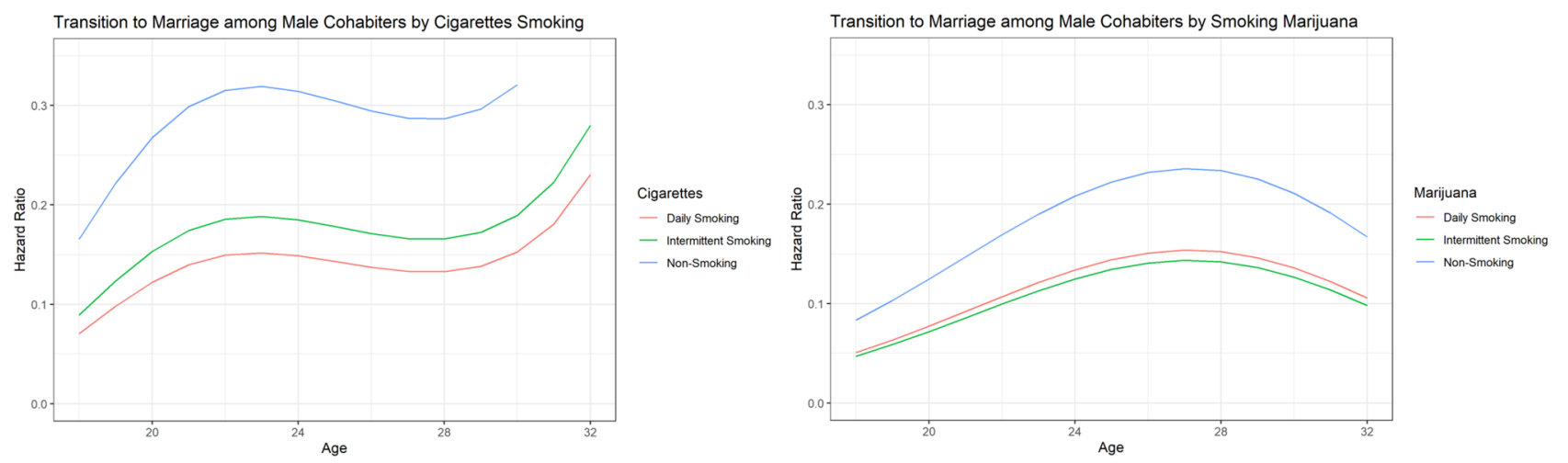

Fig. 4 Transition to marriage among male cohabiters

study. Nevertheless, this research makes a valuable contribution to the literature based on a longitudinal analysis of substance use and marital chances among cohabiters in the USA.

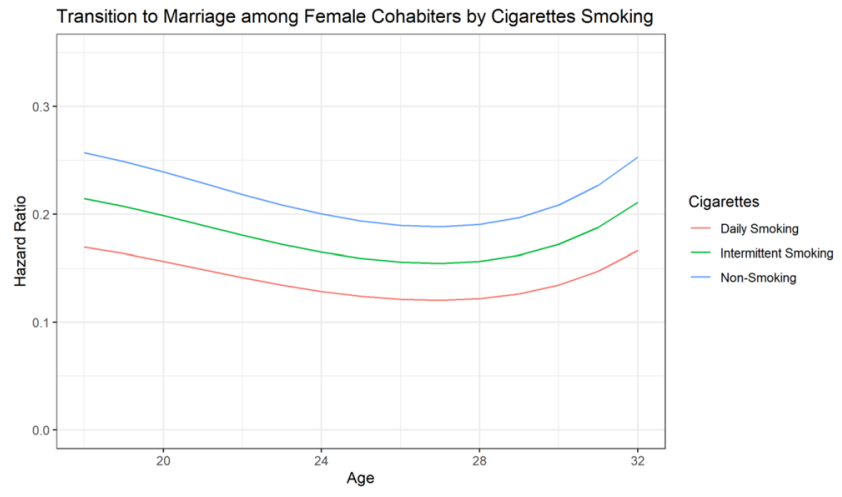

Fig. 5 Transition to marriage among female cohabiters

\section{Conclusions}

This study provides evidence that cigarette and marijuana smoking may play an important role in the transition from cohabitation to marriage among young adults in the USA. Nonsmokers of cigarettes and marijuana appear to be more likely to transition to marriage among cohabiters. Also, the mental health status of cohabiters appears to be associated with the transition to marriage. Mentally healthy cohabiters appear to be more likely to marry. This may partly help to explain why mental health tends to be better among those who are married. This study provides insight into the relationship between substance use and the transition to marriage among young adult cohabiters. As such, pre-marital policies should also address smoking habits among cohabiters to enable a smooth transition into marriage. Future studies can examine potential risky behavior patterns after marriage among previous cohabiters. This will provide a better understanding of the long-term protective effects of marriage among this cohort. Finally, an assessment of other health-related behaviors such as

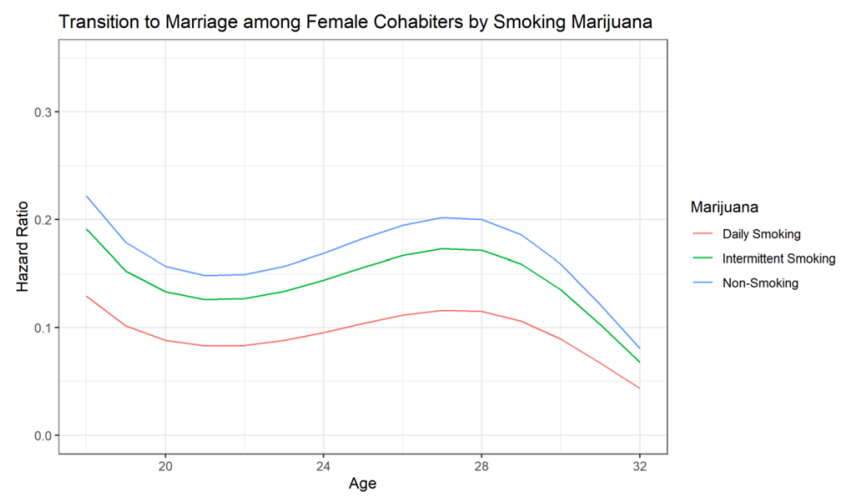

drinking and other illegal drugs can help to determine the influence of substance use in the transition to marriage among cohabiters.

\section{Declarations}

Research Involving Human and Animals This article does not contain any studies with human participants or animals performed by any of the authors.

Conflict of Interest The authors declare no competing interests.

Open Access This article is licensed under a Creative Commons Attribution 4.0 International License, which permits use, sharing, adaptation, distribution and reproduction in any medium or format, as long as you give appropriate credit to the original author(s) and the source, provide a link to the Creative Commons licence, and indicate if changes were made. The images or other third party material in this article are 
included in the article's Creative Commons licence, unless indicated otherwise in a credit line to the material. If material is not included in the article's Creative Commons licence and your intended use is not permitted by statutory regulation or exceeds the permitted use, you will need to obtain permission directly from the copyright holder. To view a copy of this licence, visit http://creativecommons.org/licenses/by/4.0/.

\section{References}

Ali, M., \& Ajilore, O. (2011). Can marriage reduce risky health behavior for African- Americans? Journal of Family and Economic Issues, 32(2), 191-203. https://doi.org/10.1007/ s10834-010-9242-z

Duncan, G., Wilkerson, B., \& England, P. (2006). Cleaning up their act: the effects of marriage and cohabitation on licit and illicit drug use. Demography, 43(4), 691-710.

Fedorova, E. V., Roth, A. M., Cepeda, A., Wong, C. F., Iverson, E., \& Lankenau, S. E. (2020). The role of life events/contextual factors and cannabis use in patterns of other drug use among young adult cannabis users in Los Angeles: a qualitative inquiry. Journal of Drug Issues, 50(2), 157-172. https://doi.org/10. 1177/0022042619900205

Fleming, C., White, H., \& Catalano, R. (2010). Romantic relationships and substance use in early adulthood. Journal of Health and Social Behavior, 51(2), 153-167. https://doi.org/10.1177/ 0022146510368930

Furstenberg, F.F., Rumbaut, R.G., \& Settersten, R.A. (2005). On the frontier of adulthood: Emerging themes and new directions. In. Settersten, R.A., Furstenberg, F.F, \& Rumbaut, R.G. (Eds.), On the frontier of adulthood: Theory, Research, and Public Policy (pp.3-25). Chicago, IL: The University of Chicago Press.

Guttmannova, K., Kosterman, R., White, H., Bailey, J., Lee, J., Epstein, M., et al. (2017). The association between regular marijuana use and adult mental health outcomes. Drug and Alcohol Dependence, 179, 109-116. https://doi.org/10.1016/j. drugalcdep.2017.06.016

Hoffmann, J. (2018). Cohabitation, marijuana use, and heavy alcohol use in young adulthood. Substance Use \& Misuse, 53(14), 2394-2404. https://doi.org/10.1080/10826084.2018.1480037

Jackson, C. (2012). Introduction: marriage, gender relations, and social change. Journal of Development Studies, 48(1), 1-9. https://doi.org/10.1080/00220388.2011.629653

Jackson, S. E., Steptoe, A., \& Wardle, J. (2015). The influence of partner's behavior on health behavior change: the English Longitudinal Study of Ageing. JAMA Internal Medicine, 175(3), 385-392.

Jang, B. J., Patrick, M. E., \& Schuler, M. S. (2018). Substance use behaviors and the timing of family formation during young adulthood. Journal of Famiy Issues, 39(5), 1396-1418.

Jo, Y. (2020). The significance of resilience in mental health promotion of married immigrant women: a qualitative study of factors and processes. BMC Women's Health, 20(1). https://doi.org/10. 1186/s12905-020-00945-3

Johnston, L. D., O’Malley, P. M., Bachman, J. G., Schulenberg, J. E., \& Miech, R.A. (2016). Monitoring the Future National Survey results on drug use, 1975-2015: Vol. 2. College students and adults ages 19-55. Ann Arbor: University of Michigan.

Klärner, A. (2015). The low importance of marriage in eastern Germany - social norms and the role of peoples' perceptions of the past. Demographic Research, 33, 239-272.
Krumpal, I. (2011). Determinants of social desirability bias in sensitive surveys: a literature review. Quality \& Quantity, 47(4), 2025-2047. https://doi.org/10.1007/s11135-011-9640-9

Kulu, H., \& Boyle, P. (2010). Premarital cohabitation and divorce: support for the "trial marriage" theory? Demographic Research, 23, 879-904.

Li, M., Geng, Z., Liao, P., Wang, X., Yang, T., Wang, J., et al. (2020). Trial marriage model-Female mate choice under male interference. Journal of Animal Ecology, 89(8), 1851-1859. https://doi. org/10.1111/1365-2656.13240

Manning, W. (2020). Young adulthood relationships in an era of uncertainty: a case for cohabitation. Demography, 57(3), 799819. https://doi.org/10.1007/s13524-020-00881-9

Margolis, R., \& Wright, L. (2016). Better off alone than with a smoker: the influence of partner's smoking behavior in later life. The journals of gerontology. Series B, Psychological Sciences and Social Sciences, 71(4), 687-697. https://doi.org/10. 1093/geronb/gbu220

Oesterle, S., Hawkins, J. D., Hill, K. G., \& Bailey, J. A. (2010). Men's and women's pathways to adulthood and their adolescent precursors. Journal of Marriage and the Family, 72(5), $1436-1453$.

Percheski, C., \& Meyer, J. M. (2018). Health and union dissolution among parenting couples: differences by gender and marital status. Journal of Health and Social Behavior, 59(4), 569-584. https://doi.org/10.1177/0022146518808707

Perelli-Harris, B., Hoherz, S., Addo, F., Lappegård, T., Evans, A., Sassler, S., \& Styrc, M. (2018). Do marriage and cohabitation provide benefits to health in mid-life? The role of childhood selection mechanisms and partnership characteristics across countries. Population Research and Policy Review, 37(5), 703-728.

R Core Team (2018) R: A language and environment for statistical computing. R Foundation for Statistical Computing, Vienna, Austria. Retrieved from http://www.r-project.org/

Rapp, I., \& Stauder, J. (2019). Mental and physical health in couple relationships: is it better to live together? European Sociological Review, 36(2), 303-316. https://doi.org/10.1093/esr/jcz047

Roghani, A., Nyarko, S. H., \& Sparks, C. (2021). The first family formation among young Americans: the role of family process. SN Social Sciences, 1(2). https://doi.org/10.1007/ s43545-020-00045-x

Schulenberg, J. E., Bryant, A. L., \& O’Malley, P. M. (2004). Taking hold of some kind of life: How developmental tasks relate to trajectories of well-being during the transition to adulthood. Development and Psychopathology, 16, 1119-1140.

Shang, C. (2012). Smoking transitions in intensity and frequency by teenagers and young adults. Available at SSRN: https://doi.org/ $10.2139 / \mathrm{ssrn} .2160911$

Shrout, M. R., \& Kiecolt-Glaser, J. K. (2020). Individual, relational, and developmental-contextual pathways linking marriage to health: reply to Brazeau, Pfund, and Hill (2020). American Psychologist, 75(1), 111-112. https://doi.org/10.1037/amp0000578

Tumin, D., \& Zheng, H. (2018). Do the health benefits of marriage depend on the likelihood of marriage? Journal of Marriage and Family, 80(3), 622-636. https://doi.org/10.1111/jomf.12471

Uecker, J. E. (2012). Marriage and mental health among young adults. Journal of Health and Social Behavior, 53(1), 67-83.

Umberson, D. (1992). Gender, marital status and the social control of health behavior. Social Science \& Medicine, 34(8), 907-917.

Publisher's Note Springer Nature remains neutral with regard to jurisdictional claims in published maps and institutional affiliations. 